\title{
Exclusão, ilegalidades e organizações criminosas no Brasil
}

IEÍCA MARIA SCHABBACH*

\section{Resumo}

O artigo discute a aplicabilidade da teoria de Niklas Luhmann ao estudo de sociedades de modernidade periférica, dentre elas o Brasil. Argumenta-se que o autor fornece noções relevantes para a compreensão de fenômenos que ocorrem nestas sociedades, cujos sistemas sociais podem não estar totalmente desenvolvidos e onde a exclusão se diferenciou, deixando de representar, ao lado da inclusão, um fator constitutivo do equilíbrio sistêmico. Nessas sociedades, a exclusão se reproduz sob uma lógica própria. Este trabalho também analisa a validade dos conceitos luhmannianos de sistema e organização social para se analisar o crime organizado no Brasil. Conclui-se que as organizações criminosas são organizações sociais, abrangendo unidades de processos de comunicação que ligam as decisões entre si. Atuando na ilegalidade, tais organizações interagem com os outros sistemas e organizações, dentro de uma rede de relações interorganizacionais, onde se percebem as linkages entre o mundo lícito e o ilícito. Além disso, para se adequarem ao ambiente externo, elas precisam sempre estar-se renovando.

Palavras-chave: Exclusão. Sistema e organização social em Luhmann. Crime organizado no Brasil.

\footnotetext{
* Professora da U niversidade de Santa Cruz do Sul, socióloga da Academia de Polícia Civil do Rio Grande do Sul e D outora pelo Programa de Pós-graduação em Sociologia, da U niversidade Federal do Rio Grande do Sul. Versão preliminar deste artigo foi apresentada no "XXV Congreso de la Asociación Latinoamericana de Sociologia (ALAS)", ocorrido em Porto Alegre, em agosto de 2005.
} 


\section{A contribuição de Niklas Luhmann para o estudo de sociedades periféricas}

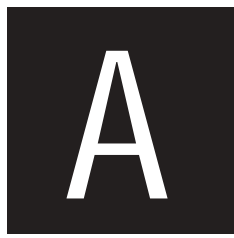

adequação da "Nova Teoria dos Sistemas" de Luhmann para o estudo de formações sociais diferentes da européia e da norte-americana é uma questão controversa que divide vários autores das Ciências Sociais. Dentre eles, Marcelo Neves (1996) afirma que não é possível aplicar o conceito de sistema autopoiético luhmanniano ${ }^{1}$ à esfera jurídica brasileira, devido à não instalação plena do Estado de D ireito no País, isto é, existiria aqui uma heteronomia funcional do campo jurídico. Para este autor, ao invés de autopoiese poderse-ia falar de alopoiese do Direito no Brasil, por conta da sobreposição particularista dos ditames dos sistemas político e econômico sobre as questõesjurídicas. Neste sentido, o insuficiente fechamento operacional resultou na inexistência de uma identidade própria do sistema jurídico, no qual até mesmo a distinção entre lícito e ilícito encontra-se indeterminada, devido à falta de institucionalização e de normas eficazes. Como conseqüência, enquanto os despossuídos brasileiros são fracamente integradose submetidosà inflexibilidade legalista, os grupos privilegiados encontram-se fortemente integrados e desfrutam de privilégios e da impunidade. (NEVES, 1996)

O próprio Luhmann reconheceu em entrevista (LUHM AN N, s/d), que sua teoria é socialmente condicionada. Por outro lado, nesta mesma ocasião, o autor argumentou que ela permite, melhor do que outras abordagens, captar a distinção entre inclusão e exclusão funcionais, existente em qualquer sociedade:

10 conceito de sistema - enquanto rede recursiva de comunicações, autopoieticamente constituída e fechada em relação ao ambiente - abrange os seguintes elementos constitutivos: 1) autopoiese (autoprodução e auto-reprodução de sua estrutura e elementos); 2 ) fechamento operacional (o sistema opera unicamente dentro dos seus limites, através de operações seletivas); 3) acoplamento estrutural (adaptação permanente e correspondência com o entorno, que obriga o sistema a se modificar permanentemente para não colapsar). A sua reprodução autopoiética acontece quando atinge a diferenciação funcional com o meio e os outros sistemas, dentro de um processo que é sempre contingente. Vide: LUHM AN N, 1991, 1997a, 1997b. 
Isto não quer dizer que os componentes europeus possam desenvolver-se como especificidades regionaisem outros lados, mas sim que determinados aspectos, sobretudo a forte acentuação na capacidade de rendimento da diferença funcional (estados territoriais, economia monetária, investigação científica, a intimidade da vida de família) só podem ser entendidos dentro de um contexto de experiência europeu. [...] Penso que, em regiões que não alcançaram o desenvolvimento, estas condições não estão suficientemente instaladas. E isto estabelece uma brecha entre os que participam da inclusão funcional (que têm algo, que podem exercer influência) e os que ficam excluídos de tudo. Creio que isto pode ser descrito com a ajuda da teoria de sistemas. E me parece que esta teoria poderia explicar melhor este fenômeno do que as teorias que trabalham com o conceito de exploração. [...] D e repente tem-se a impressão de que a teoria deveria buscar, em qualquer lugar, uma nova maneira de perceber a diferenciação. Ea mim, neste momento, parece-me que a diferença diretriz de inclusão/exclusão pode oferecer uma possibilidade de explicação, sem que necessariamente conduza a um prognóstico. Não é possível saber se chegará um momento em que esta diferenciação diminua e toda a população mundial (com uma taxa de crescimento em aumento) possa ficar inserida na inclusão funcional. (LUHMANN, s/d, p. 148 e 149, tradução nossa).

Examinando-se a citação acima, percebe-se que Luhmann reconhece a aplicabilidade de certos aspectos de sua teoria ao estudo de sociedades como a latino-americana e a brasileira - que, a princípio, não se enquadram na espécie de sociedade funcionalmente diferenciada². Em outro momento,

2 Luhmann estipula três tipos ideais de sociedades: segmentárias (baseadas nas comunidades de família e residência), estratificadas (das castas, estamentos ou estratos, grupos fechados cujos casamentos e uniões são endo e monogâmicos) e funcionalmente diferenciadas (dos sistemas funcionalmente diferenciados, que surgiram a partir do século XVIII). Apenas nestas últimas os sistemas sociais encontram-se plenamente desenvolvidos, funcionando autopoieticamente e permanecendo operativamente fechados ante 0 ambiente circundante. 
o autor afirma que não se pode caracterizar uma sociedade apenas através da forma típica predominante de sua diferenciação (segmentária, estratificada ou funcional), devendo-se ir mais além, pois outros arranjos e combinações são concretamente possíveis:

A probabilidade de um desenvolvimento oposto, por conseguinte, é assim mesmo alta, e não é raro, como, porém, de relevo as investigações sobre os países em vias de modernização, e que sob tais circunstâncias abrase um abismo apenas franqueável entre o âmbito da inclusão e o da exclusão, e que, uma vez aberto, tenda a assumir a função de uma diferenciação primária do sistema da sociedade. Tal possibilidade significa que uma grande parte da população fica totalmente privada das prestações dos sistemas funcionais, assim como, no âmbito de enfrente (o da inclusão), introduzem-se formas não previstas de estabilização, as quais, aproveitando parasitariamente as oportunidades perdidas por estes âmbitos de prestação, criam mecanismos característicos de inclusão e exclusão para manter de pé este entramado. (LUHMANN, 1998, p. 180, tradução nossa)

De acordo com afirmação de Darío Rodríguez, da U niversidade do Chile $^{3}$, nas sociedades parcialmente contemporâneas, os sistemas não estão completamente diferenciados, ou estão começando a se diferenciar. N elas são encontrados setores que passam por processos de (des) diferenciação, configurando bolsões, e a exclusão assume uma dinâmica própria. Por vezes, o que está excluído de certos sistemas, como do econômico, pode estar incluído em outro. É o que ocorre nasfavelas, cujos residentes, embora excluídos do mercado formal de trabalho e do sistema escolar, podem

3 Aula proferida no Workshop "Sociologia Contemporânea: teoria e método (desafios para a pesquisa)", promovido pelo Programa de Pós-graduação em Sociologia da UFRGS, em Porto Alegre, no dia 19/03/2003. 
estar incluídos no tráfico de drogas, nas campanhas de alimentação, nas redes de ajuda mútua, na assistência pública, etc. ${ }^{4}$

De fato, o conceito de exclusão luhmanniano emerge dentro desse debate como essencial para o estudo de países subdesenvolvidos ou em desenvolvimento:

Não escapa aos olhos de Luhmann, a situação vivida por amplos setores da população mundial que - em lugar do afirmado pelo conceito de inclusão de Parsons, no sentido de ter acesso, pela via dos papéis complementares, a todos os subsistemas da sociedade (nem todos podem ser médicos, mas todos podem ser pacientes; nem todos podem ser professores, mas todos podem ter acesso ao ensino; nem todospodem ser vendedores, mas todos podem ser compradores) - vêemse excluídos das diferenças alternativas que os sistemas funcionais oferecem: não contam com educação, nem com serviços de saúde e - inclusive - não contam com existência legal, dado que nem sequer têm a cédula de identidade que os identifica como cidadãos. Este tema é complementar ao da inclusão; é o fenômeno da exclusão e não se trata simplesmente de uma marginação, de uma falta de integração. Estes grupos podem estar e estão - fortemente integrados, mas resultam invisíveis para os subsistemas funcionais porque não contam com as condições mínimas para serem considerados. Este é o tema que ocupa atualmente o pensamento de Niklas Luhmann, com o qual ele pretende compreender aspectos da sociedade mundial que, em lugares como a Índia, ou nasfavelase vilas-miséria de países subdesenvolvidos, permanecem junto ao desenvolvimento, a riqueza e o crescimento acelerado da Economia. Como se pode ver, o esquema arquitetônico da teoria segue

4 Informação verbal do professor Rodríguez na mesma aula. 
sendo o mesmo: um olhar que conhece a partir da diferença, que contempla as outras possibilidades, a contingência do social e que descobre que, sempre em lugar de se estar no melhor dos mundos possíveis, encontramonos em um mundo pleno das melhores possibilidades. (RODRIGUEZ MANSILLA em LUH MAN N, 1997, p. XXIXXII, tradução nossa)

Não estando enquadrados plenamente em nenhum dos trêstipos ideais de sociedade estipulados por Luhmann, nos países e regiões de modernidade periférica (como a Índia, o sul da Itália e o Brasil, em: LUH M AN N, 1998) a exclusão ${ }^{5}$ ampliou-se e ultrapassou a diferenciação funcional dos sistemas, passando a funcionar como um supercódigo:

Esta lógica da diferenciação funcional entra em contradição com os fatos da exclusão, pondo de manifesto sua improbabilidade, sua artificialidade. Seus códigos valem e não valem para uma mesma sociedade. Equando tudo isso se faz tão firme que já não se pode ignorar, então é possível inferir que a distinção entre inclusão (laxamente integrada) e exclusão (integrada consistentemente) é um 'supercódigo' pelo qual, de fato, alguém tem que se orientar sempre, em primeiro lugar, se quer entender a sociedade. Tal evolução pode observar-se atualmente, sobretudo, na formação dos guetosnasgrandesurbes. (LUH M AN N, 1998, p. 191, tradução nossa, grifo do autor)

Existindo também nas sociedades funcionalmente diferenciadas- como o outro lado da inclusão e sob formas específicas - a exclusão nas sociedades em vias de modernização assume contornos diferentes:

5 No capítulo Inclusión y Exclusión do livro Complejidad y modernidad: de la unidad a la diferencia (1998), Niklas Luhmann esclarece o conceito de exclusão. Para ele, a inclusão é a face interna de uma forma, cuja face externa é a exclusão. Em situações de pleno funcionamento e diferenciação dos sistemas sociais, se há inclusão, há exclusão, a última representando um efeito secundário da operação autodescritiva dos sistemas, o outro lado da inclusão, a sua sombra lógica. 
Se se presta especial atenção ao presente estado dos fatos, não resulta difícil constatar que em muitos países - sobretudo os que estão em vias de desenvolvimento, mas não só eles, pois também ocorre nos altamente industrializados (como no Brasil e, em menor medida, nos Estados U nidos) - uma parte importante da população vive em condições de exclusão. [...] Para captar este [problema] em sua autêntica dimensão é preciso ter em conta que, com o câmbio da forma da inclusão, é o conjunto da distinção inclusão/exclusão que muda seu sentido. [...]A sociedade está aqui muito integrada, por mais que isto possa surpreender os sociólogos que, de acordo com a tradição inaugurada por Durkheim e consolidada por Parsons, associam estes conceitos com representações positivas. E está muito integrada porque a exclusão de um sistema funcional comporta, quase automaticamente, a exclusão de outros. Um exemplo tomado da Índia ilustra a idéia: as famílias que vivem na rua e não têm uma residência fixa não podem matricular seus filhos na escola. $\mathrm{O} u$, quem não tem documentação pessoal fica excluído das prestações sociais, não pode ser eleitor, nem casar legalmente. (LUHMANN, 1998, p. 189, 190, 191, tradução nossa).

Nessas sociedades, a propriedade e a família, principais fontes de recursos, são substituídas pela possibilidade de exercer influência legal ou ilegal, de acordo com as posições ocupadas nas organizações. Adicionalmente, neste contexto, pode ocorrer o entrelaçamento de grandes e pequenas redes de favores, contatos e venda de vantagens, que começam a operar parasiticamente. Tais redes geram seus próp rios mecanismos de inclusão/exclusão e seu funcionamento convive com o imobilismo da buro- 
cracia, estando transversalmente a ele vinculadas. Por vezes elas recorrem à ilegalidade, vindo a constituir joint venturesentre a política e a criminalidade:

U ma vez que tenha ultrapassado valores-limite, a ilegalidade converte-se em um recurso generalizável, aplicável para muitos fins - aproveitando, precisamente, que seu emprego não será conhecido. Q ualquer implicado pode ser ameaçado com a delação, e assim ser induzido a seguir formando parte. De certo modo, os atos ilegais são o bilhete de entrada na organização, que emprega esta vantagem da vulnerabilidade para efeito de conseguir lealdades - ou seja, o indivíduo se faz leal, poisé vulnerável. Desta maneira, sobre a base do meio autoproduzido da ilegalidade - quando não, inclusive da criminalidade, no caso das organizações mafiosas -, pode se intercambiar proteção por proteção. $O$ êxito da máfia, mas também de muitas outras condutas desviantes, pode explicar-se em virtude de que trabalhar de forma efetiva é algo que só pode ser motivado no meio da ilegalidade. E isto é assim porque do que se trata nele é, justamente, de inclusão versus exclusão. (LUH M AN N , 1998, p. 187, tradução nossa $)^{6}$

N as sociedades periféricas, portanto, a exclusão perde sua complementaridade com a inclusão, diferenciando-se e ampliando seus limites sob a forma de redes de proteção e favores, as linkages.

Dá-se por suposto os graus de liberdade dos sistemas funcionais, assim como também se pressupõe a margem de manobra decisória dasorganizações, masunse outros são vinculados de maneira que possam servir como recursos para a reprodução de linkages, o que os

6 Ressalta-se que, para Luhmann, não há uma preferência dessas redes pela criminalidade, mas certa indiferença, no sentido de que tanto faz, não se tem nada a perder. (LUHM ANN, 1998, p. 191, tradução nossa) 
impede de desenvolver sua própria racionalidade. (LUH MAN N, 1998, p. 188, tradução nossa)

O u seja, os sistemas ou organizações não chegam a se fechar e, para o ingresso neles, é decisiva a ocupação de posições em outros sistemas funcionais e organizações, que são, deste modo, utilizados parasitariamente e corrompidos. Esta situação indica que, diversamente das sociedades diferenciadas, nasperiféricas, ossistemasnão mantêm um fechamento operativo ante os demais e o entorno, abrindo-se mais e se articulando entre si.

Todavia, embora tais redes gozem de grande estabilidade e capacidade reprodutiva, Luhmann (1998) ressalta que elas não chegam a representar uma ameaça aos sistemas funcionais, cuja autopoiese é suficientemente robusta para evitar o desequilíbrio entre a inclusão e a exclusão e, assim, o seu colapso. O u seja, mesmo em sociedades de modernidade periférica, tais configurações não ameaçam a sobrevivência dos sistemas sociais operantes.

Feitas essas colocações iniciais que justificam a aplicação dos conceitos luhmannianos ao estudo de sociedades não-européias, examinam-se, na seqüência, duas categorias que julgamos apropriadas ao estudo da criminalidade organizada no Brasil: sistema social e organização. Tal proposição surgiu da análise de colocações de autores brasileiros e latino-americanos acerca do crime organizado, as quais, embora não mencionem explicitamente o sociólogo alemão, remetem para aspectos de sua obra, como se verificará na seqüência.

\section{O crime organizado no Brasil}

Diante das várias definições correntes de crime organizad o7, aqui se considera que esta espécie criminal abrange grupos organizados que reú-

7 Vide: SCHABBACH, 2007. 
nem, principalmente, adultos com trajetória delitiva e funcionam como organizações de atividades ilícitas. A sua conformação é hierárquica e permanente, com liderança estável que se impõe através da força e/ou da habilidade criminal. Tais grupos visam o enriquecimento ilícito e o prestígio, embora suas ações nem sempre sejam racionais ou instrumentais, incluindo: o tráfico de entorpecentes, o contrabando e o descaminho, o furto e 0 roubo de veículos, de cargas e de carros-fortes, o roubo a banco e a outras instituições financeiras, o roubo a postos de pedágio, a extorsão mediante seqüestro, etc. Por vezes, estes grupos especializam-se em um ou mais tipos de atividades, podem ter ramificações e comandos dentro das prisões, bem como estabelecem ligações com representantes de profissões convencionais (advogados, contadores, políticos, policiais, juízes, promotores e outros atores), a fim de assegurar a sua impunidade e desenvoltura no mundo legítimo.

Esta definição, próxima à de Abadinski $(1994)^{8}$, contempla as quadriIhase os sindicatos do crime de Sutherland (1955) e o tráfico de drogas em pequena escala (no varejo) ${ }^{9}$. Na visão de Abadinski, o tráfico de drogas é uma das características das organizações criminais não tradicionais que abrem

8 U m empreendimento não ideológico que envolve um número de pessoas em interação social fechada, organizado em base hierárquica com o propósito de assegurar lucro e poder através do engajamento em atividades legais e ilegais. As posições na hierarquia envolvem especialização funcional e podem ser designadasna base do parentesco ou da amizade, ou racionalmente atribuídas de acordo com a qualificação. A permanência é garantida aos membros que lutam para manter a empresa integral e ativa na perseguição das suas metas. Ela evita competição e lutas pelo monopólio de atividades particulares dentro de uma base industrial ou territorial. Há probabilidade de uso da violência e/ou suborno para atingir fins ou manter a disciplina. A afiliação é restrita, embora os não membros possam estar envolvidos dentro de uma base contingente. (ABADIN SKI, 1994, p. 20, tradução nossa).

9 Nisto diferimos de Prado (2006), que não considera o tráfico de entorpecentes de menor escala uma atividade do crime organizado, mas da criminalidade de massa. O ra, o objetivo nele buscado também é o de ganhar dinheiro fácil e rápido em quantidade superior à maioria das atividades legais, além dos seus grupos possuírem hierarquia definida e liderança, com formação permanente e vínculos estabelecidos com o mundo legal. 
possibilidades para negros e hispânicos norte-americanos ao se expandirem nos confins do ghetto, tornando-se, assim, empregadores de iguaisoportunidades. (ABADINSKI, 1994, p. 216, tradução nossa).

Por sua vez, Mariño (2000, p. 13) refere que o crime organizado no período recente ameaça desvirtuar inteiramente o potencial dos recursos morais. Em sua visão, a economia dos entorpecentes traz duas conseqüências graves para o continente latino-americano: a) de um lado, abre uma via rápida e eficiente de acesso aos recursos para os excluídos; b) de outro, oferece uma sobrevida (ainda que efêmera) para a violência altruísta como instrumento viável de superação do dualismo (no caso da Colômbia, do Peru e do M éxico), através do ressurgimento da ideologia política da violência, associada não apenas aos antigos movimentos revolucionários, mas envolvendo a população excluída e alguns expoentes do crime organizado. ${ }^{10}$

Além disso, a definição acima apresentada inclui grupos organizados menos abrangentes e estruturados, próximos das estruturas criminais de Llorente e outros (2002). Esses autores verificaram que, em Bogotá, a violência homicida concentra-se em uns poucos focos (no centro da cidade e em zonas periféricas), onde há a presença de estruturas criminais associadas com mercados ilegais e atividades ilícitas e do baixo mundo. As principais atividades destas organizações incluem: assalto de rua, a bancos e a carros-fortes, roubo e furto de veículos, furto a residências e a estabelecimentos comerciais, prostituição, extorsão e seqüestro, venda de drogas ilícitas, tráfico de armas e assassinatos pagos, justiceiros, grupos de autodefesa. (LLO RENTE et al., 2002, p. 8). Por suas características, elas diferem do

10 Da convivência entre presos políticos e comuns surgem grupos criminosos com táticas terroristas. Nasce o crime organizado. (SU PERINTERESSANTE ESPECIAL, 2002, p. 32). Como exemplos, têmse as organizações de presos que surgiram durante a década de 60 em torno de uma ideologia política e que, atualmente, irradiam seu poder e autoridade sobre a massa carcerária e amplos setores dos excluídos das grandes cidades (por exemplo: o Primeiro Comando da Capital em São Paulo, o Comando Vermelho e o Terceiro Comando no Rio de Janeiro), e que estão atingindo rapidamente outros espaços. 
crime organizado tradicional da Colômbia (as grandes máfias do narcotráfico e os grupos guerrilheiros e paramilitares existentes em algumas regiões daquele país, como em Medellín e Cali).

U m dos elementos essenciais para a consolidação do crime organizado é a formação de redes que protegem os seus membros contra a prisão e a condenação, as quais incluem executores da lei, representantes do Estado e políticos: Felizmente para os criminosos, a máquina política da cidade está, em geral, pronta a protegê-los, caso estejam dispostos a Ihe dar uma compensação adequada em dinheiro ou em serviços. (SUTHERLAND, 1955, p. 241, tradução nossa). Estas ligações são invariavelmente imperceptíveis e aparecem disfarçadas por negócios lícitos. O corre, assim, uma integração entre estruturas de oportunidades legítimas e ilegítimas (CLO WARD; O HLIN, 1960), uma vez que, para desenvolverem suas operações e circularem livremente no mundo lícito, os criminosos necessitam do apoio de pilotos, banqueiros, procuradores, advogados, juizes, tesoureiros, especialistas financeiros, etc.

O s autores que tratam desta temática divergem a respeito do caráter empresarial do crime organizado. Para Guaracy M ingardi (1998), por exemplo, o que distingue a nova criminalidade organizada da antiga (contrabando, piratas e bucaneiros) é o seu caráter empresarial, pois, apesar de ambas visarem o lucro, antigamente o empreendedor arriscava-se mais, enquanto que as novas organizações trabalham com uma previsibilidade muito grande, buscando reduzir o risco. Neste caso, a economia capitalista ordenada teria so brepujado a aquisição aventureira capitalista, em uma alusão à teoria weberiana. (MINGARDI, 1998, p. 10).

Estes novos grupos nascem: a) da cadeia (liga de presos, como no caso dos comandos de presos); b) da união de pequenas quadrilhas; c) de laços de consangüinidade em uma terra estranha (exemplo: "La Cosa Nostra" nos Estados Unidos); d) da associação de grupos interessados no monopólio de uma mercadoria ou serviço (como os cartéis colombianos). Dentre suas múltiplas atividades, Mingardi (1998) inclui: o tráfico de entorpecentes (embora 
com organização menos definida), as empresas de lavagem de dinheiro ou de receptação e o jogo do bicho (próximo do crime organizado tradicional).

$O$ utros autores relativizam o caráter empresarial do crime organizado. Abadinski (1994), por exemplo, afirma que as redes de distribuição de cocaína nos Estad os U nidos são informalmente estruturadas e operam de forma fluída e transnacional, e até mesmo os cartéis colombianos não são monopólios firmemente integrados, mas descentralizados e amorfos:

Não são burocráticos no sentido weberiano, mas antes coalizões ou confederações com fronteiras fluídas. Nenhum coração ou cabeça única dirige esses sindicatos. Suas atividades são dispersas entre muitos grupos de tráfico que aparentemente são mantidos reunidos através de um intrincado sistema de contratantes, subcontratantes, códigos de honra e laços familiares. (ABADIN SKI, 1994, p. 236, tradução nossa).

A ausência de organização burocrática é referida também por Alba Zaluar:

O crime organizado não tem organização burocrática, masum eficaz sistema de punição moral dos faltosose desafiadores, assim como uma rede de conexõespessoais, além de um sistema de distribuições de serviçose mercadorias que são objeto de suas práticas ilícitas e ilegais. (ZALUAR, 2004, p. 153).

Nesta mesma linha, Machado da Silva (1999) enfatiza que a criminalidade violenta organizada no Brasil não tem caráter empresarial:

As organizações criminosas atuais, embora sejam empreendimentos econômicos altamente lucrativos - no momento, prioritariamente organizados em torno do tráfico de drogas, que, entretanto, não é uma atividade exclusiva, nem parece ter estado presente nosmomentos iniciais -, não são empresas, no sentido de serem 
compostas de uma hierarquia orientada para fins coletivos. (MACHADO DA SILVA, 1999, p. 122).

Estas organizações assemelham-se, em certos aspectos, ao capitalismo aventureiro do contrabando e da pirataria marítima, pois: a) a sua lógica não é tanto a agregação livre de interesses em torno de um empreendimento coletivo ${ }^{11}$ ou a solidariedade comunitária, mas a subjugação pela violência; b) por outro lado, não é incompatível com o cálculo de longo prazo.

M uitos pesquisadores brasileiros destacam o avanço generalizado dos crimes violentos no País, principalmente a partir do final da década de 1970. Kant de Lima e outros (2000), em revisão das principais obras sobre a temática da criminalidade urbana, identificaram certa convergência entre os autores, a respeito da mudança do fenômeno naquela década, especialmente nos municípios do Rio de Janeiro, São Paulo e Belo H orizonte. Essa modificação caracterizou-se por: um aumento generalizado de roubos e furtos a residências, a veículos e a transeuntes, um grau maior de organização e de violência das ações criminais e o aparecimento de quadrilhas de assaltantes de instituições financeiras. Durante a década de 80 , vários estudos enfocaram a generalização do tráfico de drogas e a maior sofisticação das armas utilizadas nos conflitos.

Até a década de 1980, o jogo do bicho era a modalidade organizada de crime predominante no País, um jogo de azar juridicamente tipificado como contravenção penal e percebido como organização criminosa tradicional (MINGARDI, 1998). Naquela década, o tráfico de drogas emergiu como grave problema social, devido ao ingresso da cocaína no varejo (já na década de 1970), quando passou a ser negociada em larga escala e com preços mais acessíveis, seguindo as novas rotas dos cartéis colombianos. Para Wagner (2003, p. 43), até aquele momento o País era apenas uma rota do tráfico, e, a partir de então, foi assumindo a condição de um dos maiores consumidores de drogas, ao lado dosEstados U nidos. De acordo com Zaluar

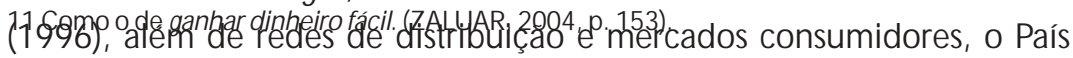
fornece insumos químicos para o refinamento da cocaína e facilita a lavagem de dinheiro, que é a base econômica do crime organizado. 
Analisand o o avanço da criminalidade violenta organizada do Brasil ${ }^{12}$, M achado da Silva (1999) destaca que ela se vem distanciando progressivamente do controle social e dos objetivos das políticas sociais, assumindo uma lógica própria:

A criminalidade organizada é uma realidade social com lógica própria, até agora não estudada, e que funciona com certa independência em relação a outros problemas e fenômenos sociais, como a 'crise do Estado'. [... ] em suma, a expansão da cidadania não garante o controle, o cancelamento ou a superação da criminalidade violenta. (M ACHADO DA SILVA, 1999, p. 115 e 123, grifo do autor).

Por sua vez, Beato Filho cita como fato novo o surgimento da violência sistêmica derivada dos homicídios relacionados com o comércio ilegal de drogas:

Nosúltimos anos temos assistido à emergência de uma nova variedade de violência sistêmica derivada doshomicídios relacionados ao comércio ilegal de drogas. Em Belo Horizonte (1998), 55\% dos 433 homicídios envolveram o uso ou a venda de drogas. Como conseqüência, homicíd iostêm uma probabilidade maior de ocorrer em territórios específicos das regiões urbanas em virtude da disputa por pontos de venda. Certamente ocorrem padrões de comportamento relativos a outros tipos de delitos. Muitos crimes contra o patrimônio ocorridosnosentornos dessas regiões parecem também se associar ao uso de drogas. M uitos usuários esgotam rapidamente seus recursos legais para consumo de drogas, recorrendo a diversas modalidades de delitos, tais como assaltos a transeuntes, a ônibus, postos de com-

12 Diversas pesquisas confirmam a hipótese de que o crime organizado não é encontrado apenas nas metrópoles e grandes cidades, mas se vem irradiando para outras localidades. No Rio Grande do Sul, ele se está difundindo para o interior do Estado (SCHABBACH, 2007). 
bustíveis ou casas lotéricas, para levantarem recursos. (BEATO FILHO, 2001, p. 2).

A esta violência sistêmica pode-se vincular, de acordo com M achado da Silva (1999), uma espécie de sociabilidade violenta ${ }^{13}$, que extingue a relação de alteridade inerente à vida coletiva e se baseia na negação do outro como igual, reduzindo-o à condição de objeto. (M ACHADO DA SILVA, 1999, p. 123). A criminalidade organizada passa, então, a reunir condutas criminosas em empreendimentos coletivose permanentes que utilizam como forma de comunicação o recurso sistemático à violência (no sentido de sujeitar o outro através da força):
A partir dos anos 70, criminosos comuns passam a or- ganizar-se em empreendimentos que se consolidam com um formato, conteúdo e sentido sociocultural marcadamente diferentes [do jogo do bicho]. Seu traço mais básico e rotineiro é o recurso universal à violência. [...] Elas também estão baseadas internamente nos mesmos princípios de subjugação pela força, constitu- indo-se em uma espécie de amálgama de interesseses- tritamente individuais, com um sistema hierárquico e códigos de conduta que podem ser sintetizados pela metáfora da 'paz armada': todos obedecem porque e enquanto sabem serem mais fracos, a desobediência implicando necessariamente retaliação física. (M ACHA- DO DA SILVA, 1999, p. 122).

Esta nova criminalidade organizada diferencia-se, na visão do autor, tanto do tradicional jogo do bicho (onde a violência era um problema secundário), quanto da máfia (que segue o modelo da lealdade familiar, ausente no atual crime organizado).

13 Tal noção aparece também em M isse (1998). Tavares dos Santose Tirelli (1999) referem uma conflitualidade violenta entre as organizações criminosas e destas para com a polícia. Zaluar (2004) menciona a reciprocidade violenta do tráfico de drogas. 


\section{Sistema social e organização em Luhmann}

O exame inicial de certas características da criminalidade organizada no Brasil - autonomização frente às políticas sociais, sociabilidade violenta, integração das organizações nas estruturas de oportunidades legítimas e ilegítimas, difusão pelos mais distintos espaços sociais - sugere que este fenômeno atingiu um patamar muito característico, lembrando as idéias luhmannianas de casualidade das estruturas sistêmicas (sua não causalidade), autonomização, fechamento operacional e autoprodução. Neste sentido, questiona-se se este fato social não se está diferenciando e formando uma espécie de subsistema social autopoiético. (LU H M AN N, 1991, 1997a, 1997b), estruturado em torno de um código específico de inclusão e de exclusão.

Esta nova esfera se teria originado da diferenciação do pólo negativo do código binário do direito (a ilegalidade), afastando-se, então, do sistema jurídico que a produziu. A partir daí, este subsistema social rompe sua relação direta com a esfera econômica e estatal, suas causas devendo ser buscadas dentro de seu próprio funcionamento (autopoiese), que envolve sempre certa casualidade e contingência.

Todavia, talvez não seja apropriado atribuir ao crime organizado o caráter de sistema autopoiético, mas o de organização, conceito provavelmente mais adequado às sociedades não-diferenciadas, nas quais as esferas sociais convencionais (direito, saber, religião, poder) encontram-se insuficientemente diferenciadas e desenvolvidas, ao contrário dos países europeus. $O$ conceito de organização surgiu na obra de Luhmann na década de 1970, e, conforme Rodriguez Mansilla (em LUHMAN N, 1997c, p. XXII$X X V)$, reúne as seguintes características:

- O rganização é um sistema cujos componentes são decisões. A decisão envolve um processo de reflexão que serve de preparação para uma ação. Ela é contingente e implica uma opção ajustada entre alternativas. 
- O s sistemas organizacionais geram seus próprios elementos, lembrando 0 conceito de autopoiese ${ }^{14}$, que foi utilizado por Luhmann somente mais tarde.

- Nem todas as decisões organizacionais seguem a adequação entre fins e meios, não pressupondo sempre a racionalidade. Nas organizações, não são os indivíduos que decidem, mas os processos organizacionais, impulsionados pela comunicação.

- A organização abrange um complexo de decisões que a unem às outras organizações, instituindo-se, assim, uma rede de relações interorganizacionais.

Mas, se as organizações compõem-se de decisões, requerem definir de uma forma compreensível as suas relações com seu entorno interno - seusprópriosmembros - e externo. Assim, os membros de uma organização 'decidem' participar ou não, ir ou não à greve, ingressar em uma organização, postular postos dentro dela ou se retirar. No entorno externo, por sua vez, há decisões de compra e venda de insumos, de aumento ou redução de impostos e taxas. Isto mostra que as organizações relacionam-se com as outras, criam organizações, ou supõem que seu entorno já se encontra organizado. (RODRIGUEZ MANSILLA em LUHMANN, 1997c, p. XXIV-XXV, tradução nossa, grifo do autor).

- As organizações são obrigadas a inovar para não perderem oportunidades. Há uma dinâmica intra e interorganizacional, nas quais as inovações são requeridas não para que as relações cambiem, senão porque cambiam. (LU H M AN N, 1997c, p. 95 e 96, tradução nossa). Através das constantes inovações, as organizações garantem a sua adaptação ao ambiente mutável.

14 Esta palavra, de origem grega (auto = próprio, poiesis = criação), apareceu na obra de Luhmann apósa década de 1970, a partir do conceito cunhado, na mesma época, pelos biólogos e filósofos Francisco Varela e Humberto M aturana. Vide: AUTO PO IESE. 
- Entre os seus mecanismos constitutivos, figuram a planificação (a decisão entre várias alternativas) e a reflexividade (a decisão sobre o próprio decidir). (LUHMAN N, 1997c, p. 47).

Luhmann refere ainda três condições estruturais - monetarização; legalização das condições do modo de vida diário; separação entre a casa, a escola e a profissão - para o surgimento das organizações, dentro de uma perspectiva muito próxima à de Weber, ao analisar a origem do Capitalismo e do Estado Moderno. O utro aspecto por ele ressaltado é a emergência de formas secundárias de organizações e dos movimentos sociais (LU HM AN N, 1997c, p. 61), a partir dos quais também se pode pensar a formação dos grupos criminosos organizados.

\section{Conclusão}

Após a análise acima realizada, conclui-se que as noções de exclusão (em nível macrossocial) e de organização (no âmbito micro) são extremamente úteis para serem analisados fenômenos peculiares de sociedades periféricas, contribuindo, assim, com a produção teórico-analítica no campo dos estudos sobre crime e violência no Brasil. Para tanto, é preciso aguçar o olhar que conhece a partir da diferença, que contempla as outras possibilidades, a contingência do social (RODRIGUEZ MANSILLA em: LUHMAN N, 1997c, p. XXI-XXII).

Tomando-se o conceito de organização de Luhmann, tecem-se as seguintes considerações a respeito da criminalidade organizada no Brasil:

a) É mais apropriado considerar os grupos criminosos como organizações que operam com uma lógica própria em torno do enriquecimento ilícito. Muito embora possuam este núcleo comum, estas organizações são extremamente distintas em suas características, escalas e meios de atuação, e quanto às habilidades de seus membros, que praticam: tráfico de 
drogas, extorsão mediante seqüestro, lavagem de dinheiro, fraudes comerciais, roubos planejados, etc.

b) Enquanto organização, o crime organizad o estrutura-se através de unidades de processos de comunicação que envolvem decisões que se interpenetram. Através delas são estabelecidas relações com os outros sistemas e organizações, sob a forma de redes interorganizacionais ou linkages (redes de proteção ou favores que impedem os sistemas funcionais de desenvolverem sua própria racionalidade, em: LUH MANN, 1998, p. 188) que entrelaçam o mundo lícito e o ilícito. 0 seguinte relato de entrevista com um chefe do tráfico de uma favela do Rio de Janeiro ilustra a existência destas redes:

- Tem gente lá na Zona Sul que ganha mais do que vocês com essas paradas aí? [repórter]

- Ganha. A comunidade é pobre.

- Não, o que eu quero dizer é o seguinte: tem uma outra ponta nesse esquema, além de você, fora daqui, que ganha com isso e que não aparece?[repórter]

- Tem, tem, tem.

- O Flávio Negão [trata-se do entrevistado] não é a última ponta dessa fieira? [repórter]

- Tem mais gente, lá fora.

- Quem é essa gente? Q uem manda em Flávio Negão? [repórter]

- Isso eu não posso dizer.

- Mas é gente importante? [repórter]

- Ah, é, muito importante. Tudo colarinho branco.

- Empresários, políticos? [repórter]

- Tem de tudo. (VENTURA, 1994, p. 201).

c) Nem todas as decisões organizacionais são racionais (no sentido da racionalidade weberiana de adequação entre meios e fins, ou de uma hierarquia orientada para fins coletivos, em: MACHADO DA SILVA, 1999, 
p. 122). Elas envolvem também valores, afetos e desafetos, costumes e atitudes típicas. Por exemplo: a subjugação pela força, a satisfação emocional ou sexual, a busca por statuse pela aprovação dos pares, a solução de uma diferença antiga com um inimigo ou a realização de alguma necessidade de justiça.

d) Estas organizações criminosas são obrigadas a inovar para se adequarem ao ambiente cambiante e se reproduzirem, mantendo a sua relação com as outras organizações e sistemas.

e) Diferentemente do que Luhmann identifica em sociedades funcionalmente diferenciadas, no Brasil, o pertencimento à organização (criminal) não pressupõe como pré-condição, a capacitação escolar e a livre escolha de uma profissão. Por conseguinte, pode-se inferir que o recrutamento de novos membros pelas organizações criminosas su rgidas dentro de um contexto de exclusão (como na América Latina) representa uma oportunidade de ganho monetário e de prestígio para a população socialmente destituída. Neste contexto específico, o critério de capacitação escolar e profissional é menos determinante para o ingresso dos novos membros.

Traduzindo-se as indicações de Luhmann para uma abordagem empírica, seria oportuno apreender qual o código binário constitutivo das organizações do crime organizado que estabelece quem está incluído e excluído e garante a motivação individual e a seleção, bem como mapear os seus demais mecanismos estruturadores, que fecham e abrem fronteiras e interfaces com os outros sistemas sociais e o ambiente, quais sejam: as linkagens e a circulação entre o mundo lícito e ilícito, as decisões inter e intra-organizacionais (racionais ou não), as inovações requeridas pelo ambiente circundante, a existência de planificação das atividades.

As contribuições dos outros autores citados apontam para a importância de pesquisar: se ocorre, de fato, a automatização da criminalidade organizada ante as políticas sociais; se a sociabilidade por ela instaurada nas 
relações sociais ancora-se, sobretudo, na violência; se as organizações criminais possuem efetivamente um caráter empresarial; em que medida elas representam um canal de acesso aos recursos financeiros e simbólicos para a população excluída; e quais as rotas principais de sua difusão.

O bviamente, um estudo neste âmbito deve levar em conta as especificidades das diferentes atividades englobadas pelo crime organizado (suas diferentes escalas de atuação, seu patamar de organização, o uso sistemático ou esporádico da violência, etc.). Enfim, para além de um enfoque descritivo e quantitativo (que permite captar as tendências e a distribuição espacial), o conhecimento mais aprofundado deste fenômeno requer uma perspectiva analítica que focalize as próprias condutas criminosas e suas referências culturais. (M ACHADO DA SILVA, 1999).

\section{Exclusion, illegality and criminal organizations in Brazil}

\section{Abstract}

The article discusses the suitability of Niklas Luhmann's theory for the study of societies of peripheral modernity, among them Brazil. It argues that the author provides relevant notions to the comprehension of phenomenons that occur in these societies, whose social systems perhaps are not totally developed and where the exclusion was differentiated, failing to represent a constitutive element of the systemic balance - as well as the inclusion - and assuming an own dynamic.

Furthermore this article analyzes the validity of Luhmannian concepts of social system and social organization to analyse organized crime in Brazil. It concludes that criminal organizations can be characterized as social organizations, covering units of processes of communication that unite decisions among themselves. Acting illegally, these organizations interact with other systems and organizations, creating a net of inter-organizational relations, or even, linkages between the licit and illicit world. Moreover, they are obliged to be always innovating in order to be suitable to the changing context.

Keywords: Exclusion. Social system and social organization in Luhmann. O rganized crime in Brazil. 


\section{Referências}

ABADINSKI, Howard. Nontradicional O rganized Crime. In: . O rganized Crime. Chicago: Nelson-Hall, 1994. p. 216-292.

AUTO POIESE. Disponível em: < http://pt.wikipedia.org/wiki/Autopoiese> . Acesso em: 13 dez. 2007.

BEATO FILHO, Cláudio C. Fontes de dados policiais em estudos criminológicos: limites e potenciais. Belo Horizonte: UFMG, 2001.

CLO WARD, Richard A.; O H LIN, Lloyd E. Delinquency and O pportunity: a theory of delinquent gangs. New York: Free Press, 1960.

KANT DE LIM A, Roberto; MISSE, Michel; MIRAN DA, Ana Paula M. de. Violência, Criminalidade, Segurança Pública e Justiça Criminal no Brasil: U ma Bibliografia. BIB - Revista Brasileira de Informação Bỉbliográfica em Ciências Sociais, Rio de Janeiro, n. 50, p 45-123, 20 semestre 2000.

LLO RENTE, María Victoria; ESCO BEDO, Rodolfo; ECHANDÍA, Camilo e RUBIO, Mauricio. Violência homicida y estructuras criminales em Bogotá. Bogotá: U niversidad de los Andes, 2002.

LUHMANN, Niklas. Entrevista concedida a Javier Torres Nafarrate y Guillermo Zermeño Padilla. Revista en Diálogo, [s/n], [s/d].

LUHMANN, Niklas. 0 amor como paixão. Para a codificação da intimidade. Lisboa: Difel, 1991.

LUH M AN N, N iklas. Sobre os fundamentos teórico-sistêmicos da Teoria da Sociedade. In: NEVES, Clarissa B. e SAMIO S, Eva M. B. (org.). Niklas Luhmann: a nova Teoria dos Sistemas. Porto Alegre: Ed. U niversidade/U FRGS, Goethe-Institut/ICBA, 1997a.p. 60-74.

LUHMANN, Niklas. O conceito de sociedade. In: NEVES, Clarissa B. e SAMIOS, Eva M. B. (org.). Niklas Luhmann: a nova Teoria dos Sistemas. Porto Alegre: Ed. U niversidade/U FRGS, Goethe-Institut/ICBA, 1997b. p. 75-91.

LUHM AN N, Niklas. Organización y Decisión: Autopoiesis, acción y entendimiento comunicativo. Introducción de Darío Rodríguez Mansilla. México: Universidad Iberoamericana / Anthropos, 1997c.

LUH M ANN, Niklas. Inclusión y Exclusión. In: Complejidad y modernidad: de la unidad a la diferencia. Madrid: Trotta, 1998. p. 167-195.

MACHADO DA SILVA, Luiz A. Criminalidade violenta: por uma nova perspectiva de análise. Revista Sociologia Política, Curitiba, n. 13, p. 115-124, nov. 1999. 
MARINO, Juan M. F. Os ciclos da violência na América Latina e a Sociologia do Crime. Trabalho apresentado no VI Congresso Luso-Afro-Brasileiro de Ciências Sociais. Porto/Portugal, agosto 2000. Mimeo.

MINGARDI, Guaracy. 0 que é crime organizado: uma definição das ciências sociais. Revista do Instituto Latino- Americano das Nações U nidas para a prevenção do delito e o tratamento do delinqüente, São Paulo, n. 8, p. 7-27, 1998.

MISSE, Michel. 0 final da cadeia: interpretações da violência no Rio. Trabalho apresentado no Seminário "Foucault". Rio de Janeiro, 11 ago. 1998. Mimeo.

NEVES, Marcelo. Luhmann, Habermas e o Estado de Direito. Lua Nova, n. 37, p. 93-106, 1996.

PRAD O , Fabiana L. A ponderação de interesses em matéria de prova no processo penal. Monografia vencedora do $10^{\circ}$ Concurso de Monografias Jurídicas. São Paulo: IBCCrim, 2006.

RODRIGUEZ MANSILLA, Darío. Nota a la versión en español. In: LUHMANN, Niklas. O rganización y Decisión: Autopoiesis, acción y entendimiento comunicativo. M éxico: Universidad Iberoamericana / Anthropos, 1997c. p. VII-XXXIII.

$\mathrm{SCH} A B B A C H$, Letícia M aria. Tendências e preditores da criminalidade violenta no Rio Grande do Sul. Tese (D outorado em Sociologia) - Programa de Pós-graduação em Sociologia/U FRGS, Porto Alegre, 2007.

SU PERINTERESSANTE ESPECIAL. Por um Brasil menos violento, São Paulo, abril 2002.

SUTHERLAND, Edwin (CRESSEY, D onald - revisor). Principles of Criminology. Chicago/ Philadelphia/New York: J. B. Lippincott Company, 1955. (original de 1924)

TAVARES DOS SANTOS, José Vicente; TIRELLI, Cláudia. A ordem pública e 0 ofício de polícia: a impunidade na sociedade brasileira. In: SO USA, Edson L. de. Psicanálise e colonização. Leituras do sintoma social no Brasil. Porto Alegre: Artes \& O fícios, 1999. p. 113-127.

VENTU RA, Zuenir. Cidade Partida. Rio de Janeiro: Companhia das Letras, 1994. WAGNER, Carlos. País-Bandido: Crime Tipo Exportação. Porto Alegre: RBS, 2003. WEBER, Max. História Geral da Economia. São Paulo: Mestre Jou, 1968.

ZALUAR, Alba. Da Revolta ao Crime S. A . São Paulo: M oderna, 1996.

ZALUAR, Alba. Integração perversa: pobreza e tráfico de drogas. Rio de Janeiro: Ed. FGV, 2004.

Recebido: $31 / 06 / 2006$ 